$\xi=-1$

\title{
Branding Image of Zero Food Waste Management Actions for Corporate Reputation Development
}

\author{
Muhamad Fazil Ahmad ${ }^{1 *}$, Aida Firdaus Muhammad Nurul Azmi², Shukor Abd Razak \\ ${ }^{1}$ Faculty of Applied Social Sciences, Universiti Sultan Zainal Abidin, Kuala Terengganu, Terengganu, Malaysia \\ ${ }^{2}$ Faculty of Applied Sciences, Universiti Teknologi MARA, Shah Alam, Selangor, Malaysia \\ ${ }^{3}$ Faculty of Computing, Universiti Teknolgi Malaysia, Skudai, Johor, Malaysia \\ *Corresponding author E-mail: mfazilahmad@unisza.edu.my
}

\begin{abstract}
Food waste is a global issue with environmental, social, and economic consequences. The problem with food waste has become more and more evident during recent years and a reduction of the waste would be one important step towards a more sustainable society. Food waste is a global issue with environmental, social, and economic consequences. As fast food industry strives to develop distinctive identities, deeper understanding about topics such as brand identity, meaning, image, and reputation will enable brand owners to communicate more effectively with stakeholders including shareholders, customers, employers, and others. Many studies have focused on investigating the sources of food waste from households, while very little is known about other outlets such as food plants and restaurants whose services contribute to the food waste amounts. The study was conducted through a literature review and interviews with the actors that included 3 QSR fast food restaurants management and 1 official from AYAMAS Food Corporation Sdn. Bhd. To broaden the scope of the research several supporting frameworks were utilized and aided in the generation of a complete understanding of the thoughts of the actors. The results from the research showed a variety of the actions they have taken to address the issue, and the opportunities and obstacles they see for the management of food waste. However, the environmental, economic, and social dimensions of the issue were acknowledged by the interviewees, being the latter the most relevant one for them, stating the importance of a change in behavior and raising of awareness and consciousness from all people towards the issue.
\end{abstract}

Keywords: Brand Image; Corporate Reputation; Food Waste Management; Triple Bottom Line; Social Responsibility.

\section{Introduction}

The food industry in Malaysia is rich in terms of tropical agricultural resources and the diversity of cultures in the Malaysian society - Malay, Chinese and Indian, led to a fascinating processed food with an Asian twist area. Increase consumer awareness of the value of nutrition and food fortification for health and created the demand for functional foods and/or healthy fresh food with minimally processed, organic and natural food flavors from plants and seafood [1].

Malaysia food and beverage market is becoming more sophisticated and supplied with both local and imported products. The strong economic growth in the late 80's and early 90's has led to significant changes in the purchasing and consumption habits. Malaysians living in urban areas are relatively aware of the brand, and they prefer, to buy in the shops or stores, they buy offer comfort and a good selection of merchandise. Lifestyle changes have led to an increase in demand for convenience food and health food. The food industry is primarily owned by Malaysian. In Malaysia, the food industry is dominated by small and medium enterprises. The most important sub-sectors are fish and fishery products, livestock and livestock products, fruits, vegetables and cocoa [2].

According to the government of Malaysia which is focusing on the area of agriculture, the processed food and beverage industry has developed to be an important part of the agro-industry. In the year
2015, attracted to the food industry for almost $15 \%$ of Malaysia's total production has RM2 billion in 75 projects. Employment in the processed food and beverage industry in 2016 fell by $5.1 \%$ to 43,080 compared to 45,418 in 2015 . The labor costs in the industry remained competitive, as its unit labor costs fell $8.2 \%$. The use and effective management of resources to small and medium enterprises account for more than $80 \%$ of the total establishments in the processed food sector [3].

Malaysia is also one of the world's leading producers of spices. In 2015, Malaysia was ranked as the sixth largest producer of pepper and chili related products (Specialty pepper, pepper sauces and processed).

Food that is not used for the purpose of feeding humans, besides representing resources that are not used efficiently, and having negative consequences for the society, the environment, and the economy, is classified as food waste. Food waste is a concept whose definition may vary depending on the country and research through which it is being analyzed. In 1981 in the research Food loss prevention in perishable crops from Food and Agriculture Organization (FAO) [4-5], food was defined as "wholesome edible material intended for human consumption".

From that research and considering the causes for loss of food presented there, food waste is defined as "wholesome edible material intended for human consumption, arising at any point of the food supply chain that is instead discarded, lost, degraded or consumed by pests". The way in which food lost and food wasted, is referred to, is generally related to the point in the food supply chain where it is lost. The two concepts used are food loss and 
food waste. Food loss refers to decrease of quantity or quality of food at early stages of the supply chain, whereas, food waste refers to the discarding of food suitable for consumption at later stages of the supply chain and it is often related to human behavior. The definition of food waste used in this report is the one provided by [6] with the consideration of the term food waste being used at later stages of the food supply chain, such as in restaurants.

Food Waste Management constitutes a global problem of significant proportions when it is recognized that 1.3 billion tons of food designated for human consumption is either lost and/or wasted yearly. Due to the relevance of the issue, the Sustainable Development Goals, Responsible Consumption, and Production, one finds halving per-capita global food waste at the retail and consumer level and reduce food losses along production and supply chain including post-harvest losses; as one of its main targets [7].

The concept of Food Waste Management derives from the application of waste management to the specific case of food, and as such, its techniques and concepts are shared. Waste management has a preferred order of applications for its techniques known as a waste hierarchy. The order of said techniques in the hierarchy goes as follows: 1 . Strict avoidance, 2. Reduction at the source, 3. Product reuse, 4. Recycling/Compost, 5. Energy recovery and, 6. Disposal [8]. The first 3 of the techniques related to the concept of waste prevention which aims at the reduction of waste amounts and hazardousness of waste [9]. The use of these techniques and application of concepts has as the ultimate goal the delivery of the benefits of waste management for each specific type of waste.

Among the benefits of food waste management, one can find a wide range of them, and those are among the three dimensions of the Triple Bottom Line. It is environmentally beneficial, because among other things, keeps food out of landfills, where it would rot and produce greenhouse gases, saving both space and resources used in the process, but also reduces water consumption and prevents forest devastation. In addition, if food waste is used for composting purposes, it can improve the soil's fertility and its capacity to retain nutrients [10]. Its economic benefits can be counted in both large and small scale, such as the reduction of disposal costs for restaurants and processors; and lowering household food bills [11]. And finally, among its social benefits, one can find the responsibility factor of not wasting edible material given the hunger experienced around the world Furthermore, when rescued food is redirected to those in need to eliminate hunger in communities, it acquires an even larger and valuable social impact.

\section{Brand Image}

The image can be defined as "the total impression an entity makes on the minds of others". Brand image has been broadly defined as the "perception about a brand as reflected by the brand associations held in the consumer's memory". Therefore, this study's approach has divided brand image components into the 'effective image' component (an emotionally dominated affective), 'generic cognitive image' component and 'specific cognitive image' component (dominated rational cognitive component) [11, 12]. The brand image components are rarely considered as one-dimensional constructs. Hence, based on the number of important aspects of the rationale for conducting several CSR activities, the survey divided the cognitive image into an effective image, generic cognitive image and a specific cognitive image component that fits all the relevant standards. This approach conforms to the idea that associations of those affected can be divided into micro-associations that specifically address the level and number of interest groups and metaassociations, whereby all parties are of equal importance to all stakeholders [13]. Moreover, various types of brand image components build the brand image. The brand image components disseminate information about the brand, which will be remembered and imparts the meaning of the brand to the customer [14].

\section{Corporate Reputations}

The definition of corporate reputation by reads as follows: "the collective representation of actions and outcomes of the past and the pre-set of the organization that describes its capability to obtain valuable outcomes for different stakeholders" (pg. 362) and this definition is used in this study. However, [15] defined corporate reputation as a reputation built on objective representations of images of a society over time and depends on the program's identity of a company, its performance and how populations perceive the behavior of several constituencies. Thus, after considering the definition of other authors, it is noticed that the characteristics of reputation are similar to that of [16]. Likewise, [17] stressed that the past and future, as well as the different stakeholders, are involved in the creation of reputation. Ultimately, the definition was adopted in this study because it captures the fact that the company's reputation is a broad concept that incorporates the various aspects of an organization and its stakeholders. From internal factors such as products to external exercises such as customer relationship management, the reputation is differentiated only by the "brand image". In addition, it includes a broad definition and the literature claims that the corporate reputation is far from agreed upon in the subject field.

Therefore, based on the above interpretation, the present study will look into whether Brand Image positively influences the betterment of corporate reputation management. Trends form the perceptions of stakeholders about critical businesses and managers are invited to lead a focused, active and central access to the scientific attitude of these stakeholders. As the attention of management and the value that has created the reputation arises, it holds the academic focus towards the study. Nevertheless, due criticism should be exercised because of the lack of discourse about the existing merchandise and its use in the world of corporate reporting regarding descriptions of corporate reputation.

\section{Food Waste Impact}

When food is not used for the purpose of feeding humans, it is established that the resources are used inefficiently, resulting in negative consequences at the societal, environmental, and economic level; in this sense, food waste is one of the sustainability issues that need to be addressed.

\section{Areas of Impact}

Food waste has substantial negative economic, environmental, and social impacts [18]. In [21], it is highlighted how food waste has an impact on food security, food quality, economic development and on the environment. In [19] also pointed out towards how food waste has impacts on a societal, environmental, and economic level on the sustainability of the food sector. The social impacts of food waste range from how an increased demand for food raises its price, to how a reduction of food waste could represent a major strategy to feed the growing world population.

Understanding that around one-third of the global food production is wasted and over 800 million people suffer from chronic hunger, represents a major step towards grasping the social impact of food waste. The social impact of an increasing food price relies on the fact that a lower price might represent more access to food for consumers. Furthermore, hunger undermines all other humanitarian and development goals.

According to FAO, hunger and malnutrition social costs are very high, being that those are pillars for human health, well-being, and physical and cognitive development. Inadequate solid waste management can have several negative impacts on the health of people, especially, when waste is disposed of in open sky landfills, 
where a significant amount of food waste goes, they contribute to the proliferation of diseases.

These environmental impacts derived from food waste also have an economic impact which based on producer prices can be estimated at USD 750 billion. The economic impacts of food waste affect as shown in both the producer and the consumer. In the case of the producer, it represents the loss of resources which have a cost such as a fossil fuel for storage, processing or distribution, or any other kind of energy employed, water, labor, and raw materials, as well as organization and planning costs. Any type of waste along the supply chain and production chain represents a cost for the producer and an ill-managed resource. For the consumer, if food is discarded, it represents a cost and loss of economic acquisitive power for a resource that was not consumed or taken full advantage of.

It is also important to acknowledge and consider the reasons, which are related to the impacts presented, as to why the wasting of food should be considered as an unethical behavior.

\section{Ethical Considerations of Wasting}

Any behavior that results in the wasting of resources should be considered unethical, given that this kind of act prevents people in dire need of said resources to attain them. All around the world, 800 million people are suffering from hunger or food insecurity, which if considered, would place the wasting of food as an unethical or immoral act. Wasting food shows a lack of consideration towards people who would have loved to have that resource, it also shows a lack of consideration towards the importance of food, of the fact that people are dying all around the world of hunger, and of the fact that food banks struggle to find and provide enough food.

In addition, the wasting of food has embedded the wasting of other valuable resources such as water, oil, and land; a fact that adds to considering wasting food as unethical. As shown in the section above, wasting of food has impacts at an environmental, social, and economic level, which, if analyzed as an issue with such a broad range of negative effects, derives in the conclusion of how behaviors that do not address this issue are devaluing its true and hard consequences.

\section{Food Waste in the Hospitality Sector}

The literature on food waste management in the hospitality sector is scarce. And studies that focus on the reasons for wasting food are also limited, where the most prominent ones on the matter are focused on household food waste in the UK, USA, and Australia. This section focuses on the causes, sources, as well as different prevention measures and actions taken to address food waste

\section{Causes and Sources}

As stated before, the literature on food waste management in the hospitality sector is scarce, however, some existing studies can shed light on the causes and sources of food waste, which they might be applied to restaurants, part of the hospitality sector. It is how food waste account for $56 \%$ of the garbage from restaurants which hint at how edible food might be part of that $56 \%$.

Food waste sources from restaurants can be divided as in [20] based on its generation source, division that comprised the preparation waste and customer plate leftover waste. Furthermore, purchased food that afterward is lost food waste could represent an additional source of food waste. In [20] based on a previous research conducted by the Sustainable Restaurant Association in 2010 , defined the preparation waste as waste generated from "overproduction, peeling, cutting, expiration, spoilage, overcooking, etc.". And, they defined Customer Plate leftover waste as" "food discarded by customers after the food has been sold or served to them". Other causes and sources of food waste are dependent on the way the restaurants operate and provision for food, together with the basis on which the food is prepared and/or served. Poor stock rotation, over preparation, inadequate portion control techniques, inappropriate storage of stock, quality of food, frequency of delivery of ingredients to the restaurants, menu variety, portion sizes, style of food service and inaccurate forecasting of consumer demand, among the factors of food waste generation. The sum up sources and divide food waste into five categories depending on where they originate: Storage losses, preparation losses, serving losses, and plate waste, and leftovers. In the study: "Food Waste in the Swiss foodservice industry" presented by [21], the results showed that from the $100 \%$ of waste, $60 \%$ were serving losses, $25 \%$ plate waste and $10 \%$ preparation losses.

The fact that one of the most mentioned causes for food waste in restaurants points towards the customers highlights the importance of stating as independent causes of food wasting consumer-related factors. The reasons found in studies that delve deeper into this area could serve as a basis for further research in other ambits, such as the hospitality sector. Among the reasons found for wasting of food in households, "consumer attitudes, values, and behaviors towards food" and different degrees of food knowledge impact the individual's tendency to waste food, which supports and could also explain the underlying factors of an important amount of food being wasted in restaurants due to consumer's plate leftovers. Causes of food waste from consumer-related factors also include the lack of planning and purchase, storage, preparation, and reuse of the food, which also resembles the causes found in restaurants as of reasons of food wasting; as changes in food offered could increase food waste for a period of time.

Furthermore, aspects such as time constraints and little regard towards food waste reduction behaviors, knowledge in storage and cooking, a culture of consumerism and abundance, food price, appearance as extrinsic cue of quality, confusion on data labelling, habits and perceptions of the consumer, lack of connection between consumers and production, and overall, the macroeconomic factors of legislation and technology, such as economic incentives or disincentives may be reasons for oversupply, inefficiencies and finally, causes for food wastage.

\section{Prevention Measures and Actions}

Whatever the causes and sources for food waste, the intention of different entities among which the hospitality sector and restaurants specifically are included, is to avoid and prevent this from happening. Among the strategies and actions that could, and in some cases, have already been, set up to reduce food waste in the hospitality sector are: Increase of staff awareness of the issue through rewarding specific actions, and focus of restaurants on their waste amounts and their origins. Other strategies include menu engineering, activity-based costing, food waste tracking, reduction of plate size, customers fining, donation of food leftovers, bio-treatment alternatives such as anaerobic digestion and composting, delivery checking to verify for contaminants, damaged packaging, expiry date; locally sourcing products, First In, First Out (FIFO) approach in inventory, storage practices to allow air to reach fruits and vegetables, avoidance of over trimming during preparation, and minimization of starters portions. Other options as means of preventing food waste are the targeting of social norms; for example, sometimes as a customer, asking for a doggy bag is not socially accepted, but, the restaurants may offer them instead of waiting to be asked for one. In [21] listed measures for food waste reduction, classifying them according to where they are generated, i.e. storage and purchase, preparation and cooking, serving at a counter and, consumers. Among the measures to prevent or reduce food waste in storage or purchase are: Optimization of storage management such as periodic control of date of expiry; other measures include use of food near date of expiry, long-term analysis of meals sold in order to adapt food orders, enhancement of order interval and no stock 
buying. Among the preparation and cooking measures, one can point towards strategies against overproduction, reuse of leftovers, control of preparation losses and training of employees, and fast cooling down of food to prevent the growth of microorganisms. And, among measures to prevent food waste directed to consumers are the sensitization of customers to the field of food waste and its causes with for example posters, communication to consumers to increase their tolerance for sustainability measures, research regarding reasons for plate waste through surveys; and donation of food to local charities.

The legislation also plays a key role in the achievement of a successful food waste management. Practices derived from laws and regulation include the introduction of requirements such as food waste reporting and standardization for food waste calculation, standardization of expiration date labels for food, and recommendations oriented at the recollection of food waste from households and food service sector separately. The actions oriented to waste management in the hospitality sector as means of identifying and further reducing and managing the food waste, among other kinds of wastes that are being generated. Such actions include the selection of a waste carrier, the conduction of a waste audit, the implementation of a solid waste management program based on the waste hierarchy, the employment of green purchasing, the training of staff and encourage their participation and feedback in the program, and the involvement of customers in the program. Figure 2 presents in a graphic way, the waste hierarchy, and actions that could enable the achievement of each of the options. The Waste Hierarchy presented by the EU Waste Framework Directive is further discussed in the Theoretical Chapter of this research. Food waste management as a direct action taken towards the eradication of hunger needs, besides the aforementioned points, as the FAO puts it, needs that all sectors of society make efforts to reduce their waste and losses, which would then have an impact on the livelihood of millions of people, as well as a deep change of mentality.

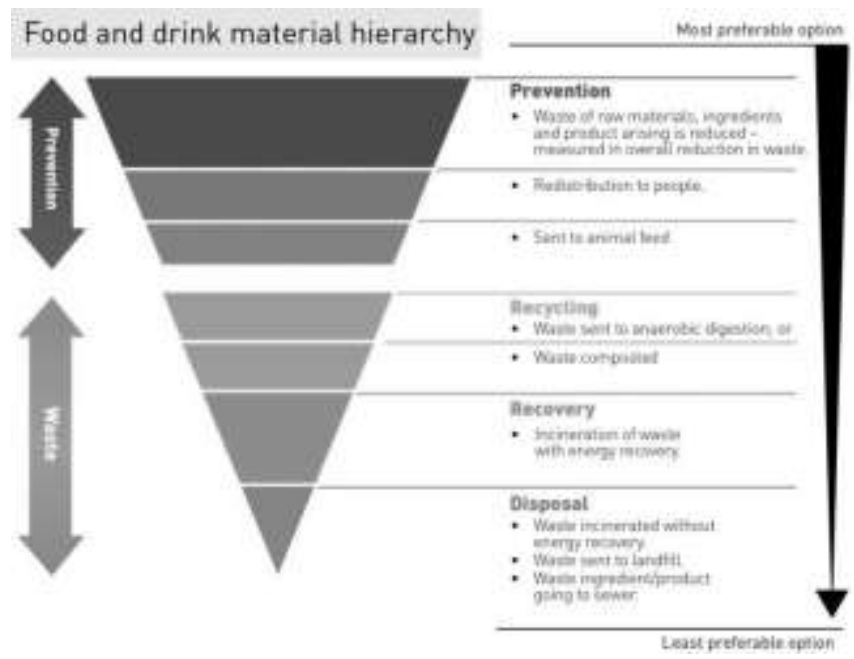

Fig. 1: Food and Drink Material Hierarchy [18]

\section{Discussion}

The KFC Malaysia story began with the opening of their 1st restaurant on Jalan Tunku Abdul Rahman in 1973. There are currently over $600 \mathrm{KFC}$ restaurants nationwide serving Malaysians great tasting chicken 365 days a year. As the No. 1 fast food and leading QSR brand in Malaysia, they are constantly working to better serve their customers with great moments, excellent services and 'Finger Lickin Good' food. KFC Restaurants constitutes the fast food service type of restaurant selected, the restaurant's managers were the actors which provided the information to be presented in this subsection, obtained through a semi-structured interview.

\section{Food waste and its impacts}

For one of KFC Restaurant's manager, food waste does not represent a problem as such, but he describes it as unconsciousness towards the waste each person produces; and that it shows a lack of regard for the value of the food one is eating. Referring to food waste from restaurants, he recognizes how people show a lack of conscience when ordering food and the decision they face afterward of whether eating it or not. Also, referring to food waste from restaurants in the preparation process, he acknowledges that in some cases it should not be necessarily considered as waste since you might be able to re-use and reprocess some of the food remnants. The impacts derived from food waste are, as seen by him, mainly on the environmental aspect and are the result of the combination of the following facts: 1. How waste, in general, is not classified in Malaysia, from businesses or households, 2. How it all ends up in the landfill of Malaysia City, 3. The current state of the said landfill, and 4. The negative consequences of food waste on landfills. He also sees food waste as having a social impact related to how some people make a living out of what other people throw away, noting how "what for a lot of people is useless", becomes the main asset for others. In addition, he views food waste having an economic impact for both the party that is throwing away the food and for whoever needs to collect it and treat it afterward. Thus, food waste has an economic impact that affects individuals, companies, and the country.

\section{Restaurant food waste generation and food waste management initiatives}

The KFC Restaurant's manager recognizes that the subject, in terms of restaurant food waste, should be divided in two: Food waste from fast food chains, and food waste from normal or traditional restaurants, which include restaurants that serve homemade type of food, and how he categorizes KFC Restaurants. $\mathrm{He}$ believes that given some of the quality standards and sales goals set by fast food chains, their food waste generation is greater than that of traditional restaurants. He states that the reason fast food restaurants, like KFC Restaurants, might generate less food waste is due to the ability to estimate how much you could use during the day and the ability to reprocess and re-use some food remnants in other dishes [21].

$\mathrm{He}$ attributes food waste generation to a behavior characterized by carelessness, but also, he believes that food waste from customers of the restaurant comes from their shame or embarrassment of asking for a "doggy-bag" to take the rest of their food home. He states that food waste generation is greater on what clients leave on their plates than what it is being wasted in the kitchen. Nevertheless, he mentions how portion sizes and a consumerism behavior also have repercussions on the amount of food that is being wasted. He goes on and points towards how little food, restaurants referring to them as food producers, are wasting or throwing away. KFC Restaurants has never actually measured food waste generated in the restaurant, specifically in the preparation and storage stages, but its manager estimates that this should be under $2 \%$ of all the food that is bought.

Wasting of food has been approached by the restaurant in the following ways: KFC Restaurants has the practice of giving whatever food they have as leftover to the kitchen personnel. He believes that involving the personnel is key for reducing food waste and not only in the restaurant but they might also replicate this behavior at home. In addition, they have changed the food quantity they get from the downstream by lowering their food obtaining frequency, which resulted in a lower inventory level preventing waste that was generated from the deterioration of food and vegetables in storage.

He states that some actions towards preventing food waste, bring with them the use of additional items that could be harmful to the environment, such as styrofoam or plastic containers to give to 
customers to enable them to take their food home. From food waste management initiatives, KFC Restaurant's manager believes that reducing portion sizes is not an actual solution, since in his opinion; people will leave food on their plate no matter their portion size.

\section{Incentives, opportunities, and obstacles for food waste management}

KFC restaurant's manager states that in his personal case he already has all the incentives he needs for addressing food waste and managing it, in what he describes as being able to enjoy a green world. However, he believes that for other people to engage actively in food waste management, an economic incentive would be the logical approach being that people "tend to monetize things" and how people "want an economic incentive", nevertheless, he does not think this kind of incentive should be the one that should be promoted, but a social kind of motivation, in which people realize that taking care of the environment goes beyond economic benefits. He also visualizes how programs oriented towards people and communities with topics regarding environmental awareness could help the next generations to have a better world; programs in which everyone should be involved from businesses to NGO's, and that could start in elementary schools around the country.

KFC Restaurant's manager does not envisage a clear benefit for restaurants from addressing the food waste issue; but he does see it as an opportunity to contribute with society and his country by acting responsibly while conducting his activities, in this case, the restaurant's activities. In KFC Restaurants, they understand how every action, no matter how little matters and by doing this something can be achieved. However, Malaysian idiosyncrasy, the negativity of its people, and their focus in issues whose consequences are perceived as more immediate are seen as the main barrier to address and emplace food waste management strategies.

\section{Food Waste and its Impacts}

The definition of food waste and the impacts it has, given by the interviewed actors shared some commonalities, but also certain differences were noted. For KFC restaurants' manager food waste was not a problem, but a lack of awareness from whoever was wasting the resource. For another manager food waste was a delicate and complex subject; and for another one, food waste was the personification of a bad habit. These characterizations of the subject show a tendency of the perception of food waste towards the social aspect of the issue. However, the impacts that the actors considered food waste has, included aspects of both the economic and environmental ambits, being the environmental aspect of the one that showed a more diverse range of opinions.

Regarding the economic aspect, all interviewees pointed out towards how, in their opinion, food waste has a significant financial impact for the producer or restaurants in this case Additionally, KFC restaurant's manager mentioned how it migh also entail an economic impact not only for the businesses but for the country as the waste management is in their hands. For the actors, the economic impact of food waste on the producer is apparent in the inefficient use of a valuable resource, and how food waste could increase the operating costs of the company. As stated by the informant: "the more food you throw away the more you spend". These perceptions are in line with the research by the FAO where it is stated how economic impacts of food waste affect the producer by representing a loss of resources such as energy, water, labor, and raw materials, all of which entail a cost for the company. Additionally, according to a tone of the informant, wasting food could have a negative impact on the image of the restaurant, generating undesired attitudes from both clients and employees.
This could also be argued to have an economic impact, by generating rejection from clients towards the restaurant and the employees being careless in their management of food, adding costs to the company. In the aforementioned report by the FAO, the economic impact for the consumerism stated as a cost and loss of acquisitive power for a resource that was not fully taken advantage of. It is, however, worth noting how none of the interviewed actors mentioned food waste as having an economic impact on the consumer. This apparent lack of recognition towards the economic impact on the consumer could be attributed to the influence of the actors' position and responsibilities, them being interviewed as restaurant managers. Overall, the perceptions of the actors towards the economic impact of food waste could be linked to 17 Goals of the UN sustainability agenda, more specifically to responsible production given the inefficient use their resources, starting by food itself, but also related to energy and labor, which all represent a cost for the company, employed for its production.

The social impact of food waste was the most relevant aspect of the issue according to the perception of the different actors. It was so, that two of them even included a social component in the general description they provided about food waste. Characterizing it as an unconsciousness in the person generating waste, a lack of regard for the true value of food and a bad habit. The actors related the social impact of food waste to the moral and ethical aspects that this action represents. Particularly, it was brought up by all the actors, how wasting food was an incoherent and inappropriate behavior, due to the fact that people around the world, or specifically in the country, need the resource. Consumer and cultural behavior were pointed out as the main driver of the social impact of food waste.

All the actors showed particular regard and interest, as well as awareness, towards the number of people who suffer from hunger, and it was mentioned how what for a lot of people might be useless, could represent a significant resource for others. The perception of the actors in this aspect finds many similarities with statements found throughout the literature in this matter. The actors understanding the relevance of food waste towards achieving food security would represent a major step towards grasping the social impact of food waste. This step is accomplished when it is understood that around one-third of the global food production is wasted and over 800 million people suffer from chronic hunger, which probably is not completely grasped by the interviewees, but the general idea exists. Additionally, the actors referring to food waste as unethical, where it is stated how any behavior that results in the wasting of resources should be considered unethical. Moreover, the lack of consideration for people and lack of regard for food's true value mentioned by the actors.

The perception and description received from the different actors regarding the environmental impact of food waste ranged from a topic that had not been given much thought to a detailed explanation of waste management in Malaysia. For two of the respondents, the environmental impact of food waste was unclear. For one of them, the environmental impact of food waste depended on the food. Meanwhile, for the other one, food waste has an environmental impact but could not clearly specify which one. Instead, he pointed towards how the restaurant's operations on the delivery and transportation of their products were the ones generating the environmental impact.

It is worth observing how the uncertainty regarding the environmental impacts of food waste for some of the actors, could be related to the fact those impacts have not yet been analyzed in depth in any study as pointed out by FAO. However, for one informant at KFC Restaurants, the impact of food waste was mostly at the environmental field, where he mentioned specifically the impact that food waste on landfills has on the environment, along with how in Malaysia waste is not classified and all end up in a landfill. This statement by him echoes what is the impact of methane gas generated by food waste rotting in landfills. The perception of the actors towards the environmental impact was inclined towards climate change and its impacts, in terms of 
implying the effects of carbon dioxide from transport, and methane produced in landfills from rotting of food on the environment.

\section{Food waste generation and food waste management initiatives}

The respondents mentioned different stages where they perceived food waste occurred, together with various reasons for its generation. At Ayamas was considered influential for the level of food waste generation. At Life Region Food, moments during preparation were seen as possible foci of food waste; while at KFC commissary, storage and handling of vegetables and buns were presented as a pertinent source of food waste. These could all be considered or related to the economic dimension of food waste generation, given their business-like characteristics such as the type of service provided by the company, or as part of the production process

All respondents mentioned as relevant the food being wasted by customers either directly or indirectly, to the extent that 2 out of the 3 restaurant managers interviewed, stated how consumer food waste was, in their opinion, greater than that from their own preparation and production of meals. Despite none of the respondents had ever measured how much food waste they generated, two of them considered their food waste as being relatively low based on empirical observation. The same two respondents considered that food waste in fast food service restaurants could represent the opposite scenario where, in their opinion, more food is wasted during preparation in the kitchen, than that from customers. This statement was reinforced by how the fast food restaurant, which at one moment considered themselves as a fast food restaurant, believed that their preparation and storage of food waste was greater than leftovers from customers. The reasons, pointed as possible contributors for food waste from customers, were lack of awareness from the customers, in addition to a lack of knowledge about portion sizes and consciousness about how much they are capable of eating. Furthermore, a cultural behavior in which asking for a "doggy bag" is a reason of shame or embarrassment also contributed, in one of the respondent's mind, to an increase in the food being wasted. This source of food waste is more inclined towards the social dimension, being customers and their behaviors, which contribute to the generation of waste.

Among the practices that were adopted by the restaurant managers to minimize food waste one can find donation of leftovers for personal or public workers, promotions in which surplus from food preparation are given to customers, changes in food procurement strategies which included agreements with the suppliers in terms of quality of ingredients and delivery frequency, involvement, and awareness campaigns with the employees. Reuse of food leftovers for preparation of other meals or dressings, as well as tests directed to forecast the yield of the different ingredients, were other initiatives that were brought up.

There is no measurement or regulation, that they know of that require them to do this any differently. So, at the last level of the hierarchy, there is not any kind of action or strategy to address or minimize the impact of only disposing waste, including food waste, which ends up in the City's landfill. In addition, none of the respondents gave clear examples of actions taken in order to optimize storage management, which is one of several possible prevention actions mentioned in the literature.

The sources of food waste that were mentioned by the respondents, all of them are mentioned in previous studies related to the subject. Particularly, in the frequency of delivery of ingredients to restaurants, style of food service, and inappropriate storage of stock are mentioned.

Moreover, despite not, all the sources of food waste mentioned in the literature are referred directly by the interviewees, the actions, and initiatives they have taken to address the issue, implying their recognition of them, and are found as prevention measures of food waste in the literature. Such is the case of training, rewarding, and recognition for employees, an increase of staff awareness. Losses originated in storage, preparation or serving. Or, actions such as food procurement strategies, which could include frequency of delivery of ingredients to the restaurants, and the feeling of shame from customers, mentioned by the interviewees, both, as means of preventing food waste and in the case of the latter, by targeting social norms.

The actions taken by the respondents show genuine interest towards the food waste and its management. Moreover, restaurant managers resorting to donating their surplus of food (at oversea but in Malaysia not yet implemented), to avoid it going to waste, shows awareness and a high regard for the topic. The Municipality of Malaysia City also showed an important approach towards food waste management by transforming food donations from the markets into meals for young people at educational centers. This prevention measure of food donation and it strengthens the belief on how their motivation for action, is not only on an economic dimension but also on a social one.

\section{Incentives, opportunities, and obstacles for food waste management}

The actors were asked what would be an incentive that would make them engage more actively in food waste and its management. Their answers were classified using the Triple Bottom Line Framework. QSR brands leaned towards an incentive that could be classified within the environmental dimension since he mentioned that all the incentives he needed were to be able to enjoy a "green world". However, he pointed out how, traditionally, people seek for an economic incentive, although he would rather promote a different type of incentive focusing on the benefits of taking care of the environment. Ayamas informant, inclined towards the social dimension, and suggested an incentive that promoted a sense of awareness towards the issue of food waste in which an emotional message could be portrayed. He mentioned the creation of a video or documentary in which people battling hunger could feed themselves because people stopped wasting food. The informant at Life Region Food, also inclined for an incentive that promoted a sense of awareness. While informant form KFC restaurants manager stated clearly how realizing the cost and potential savings from food waste management would be the main incentive for them to engage in such activities, which places their statement on the economic dimension of the Triple Bottom Line Framework. The actors interviewed appear to agree on the fact that an economic incentive directed to address the wasting of food would result in a higher level of success with more people, although not necessarily with them. Nevertheless, their position on who should promote those incentives varies; presenting the company, business themselves, and a joint effort of several institutions as possible sponsors.

Among the opportunities that food waste offer on the economic dimension, the informants mentioned composting as a side business alternative, optimization of restaurant resources, and controls and information systems based on yield and loss of ingredients during production. A technique such as food waste dehydration, composting, in which the food waste is used, and avoids its disposal to landfills, could also be categorized in the environmental dimension of the opportunities mentioned by the actors. On the social dimension, among the opportunities for food waste management, the actors envisioned the creation of policies to instruct and guide employee behavior when handling food and food waste, as well as contributing to society and the country by acting responsibly. The legislation regards as a key in the achievement of a successful food waste management, is not mentioned by any of the respondents as possible approach or opportunity, despite having mentioned that there is no law, to the best of their knowledge that addresses the issue.

Finally, the obstacles perceived by the actors, can all be classified in the social dimension of the Triple Bottom Line Framework, 
given that they refer to the behavior of both employees and customers, cultural behavior, mentality and idiosyncrasy of Malaysians, as well as limited capacity to influence customer practices as a restaurant owner or manager, as main barriers to address the issue and implement prevention and minimization measures. The fact that raising awareness was not a tangible function that could be executed by the Municipality was also pointed out. Time and cost are also mentioned as obstacles for food waste management, which could be further classified as economic factors.

The limited capacity of restaurants to influence customers could be disputed since it could be addressed with an approach of sensitization of customers to the field of food waste and its causes with for example posters, communication to consumers to increase their tolerance for sustainability measures, research regarding reasons for plate waste through surveys; and donation of food to local charities. In this same line, the lack of control over restaurants argued by the company could also be debated.

\section{Conclusion}

Food waste, as found in several pieces of research has negative implications on an environmental, economic, and social level. It is also seen as part of the compound of actions needed to address the food security issue that the world's population faces. These realities have positioned food waste and its management on the global agenda. Nevertheless, Malaysia, part of ASEAN which accounts for $6 \%$ of the global food loss, still lacks concrete strategies to address the issue. And, the insights of diverse actors in the country with direct relation to the management and handling of significant amounts of food remain unidentified. This research intended to shed some light on said issue focusing on actors in or related to restaurants located in the urban city in Malaysia. The research sought to do so by delving deeper into the perceptions of the actors towards food waste and food waste management; in addition to how they handle it now, and what could promote a more active engagement in the issue.

In order to classify and categorize the perceptions of the interviewed actors, the concept of Sustainable Development, the Sustainable Development Goals, and the Triple Bottom Line were used as overarching frameworks. To broaden the scope of the research, an approach based on Positional Analysis, where organizations and persons are considered beyond the economic approach, was utilized. Furthermore, understanding how the meaningful involvement of all people, in decisions and topics that might have an impact on them in any way, through Environmental Justice, guided the selection of different actors.

The research shows how different actors used several ways to refer to food waste, and understood its impacts in diverse manners. However, impacts on an environmental, economic, and social dimension were acknowledged by the interviewees; being the impacts at the social level the most relevant ones. Additionally, they all recognized as an economic dimension, how food waste represents a cost for restaurants. It appears as if the environmental dimension of food waste and all that it entails, is the least important for the actors, and where their knowledge of the impacts it has is more limited.

As with the impacts, actors had diverse perceptions of where and how food waste is generated, and several stages along the production chain of food production in the restaurants where mentioned. However, all of them mentioned customers as important food waste generator, and the majority regarded them as the main contributor. The actors agreed on how the type of service a restaurant offers, marks an increase, or decrease in the food waste generated. Their regard towards food waste generation and their interest in addressing it seems legitimate, as shown by the broad range of actions taken by them to do so. These actions range from food surplus donation, all the way to negotiations and strategies arranged with their ingredients suppliers.

The actors seem to favor economic incentives to address and motivate food waste management, given its apparent appeal to a greater number of people. Nevertheless, they see other options and incentives as viable such as the creation of policies by the restaurants, awareness campaigns, and side-business opportunities by composting. Finally, all the actors identified as the main obstacle to the behavior presented by the consumers, and their limited ability to go beyond their responsibilities to change food waste generating behaviors from them

The research offered an initial step on which to build to develop strategies at a company level regarding food waste management in restaurants. It showed the opportunity to conduct more focused researched fast food chains. In addition, further investigations on the behavior of customers and people in general towards food and what motivates them, as well as ways to promote and enable changes in it, appear as an option for a valuable contribution to the issue. These are just a few possibilities that arose for future research to be conducted, in a topic that might well be the first big step to tackle the challenges that humanity is facing and will continue to confront to warrant food security.

\section{Acknowledgement}

The authors would like to thank QSR Brand (M) Holdings Sdn. Bhd. for CEO Faculty's internship and the Research Management, Innovation and Commercialization Centre, Universiti Sultan Zainal Abidin, Terengganu, Malaysia for providing the financial assistance to support the publication fee of this article.

\section{References}

[1] Pirani, S. I., \& Arafat, H. A. (2014). Solid waste management in the hospitality industry: A review. Journal of Environmental Management, 146, 320-336.

[2] Othman, J., \& Jafari, Y. (2014). Selected research issues in the Malaysian agricultural sector. Jurnal Ekonomi Malaysia, 48(2), 127-136.

[3] Galanakis, C. M. (Ed.). (2015). Food waste recovery: Processing technologies and industrial techniques. Academic Press.

[4] FAO, IFAD, and WFP (Food and Agriculture Organization, International Fund for Agricultural Development, and World Food Program). (2014). The state of food insecurity in the world 2014 Strengthening the enabling environment for food security and nutrition.

[5] Fao, I. (2013). WFP, The State of Food Insecurity in the World 2013 - The Multiple Dimensions of Food Security. FAO.

[6] Parfitt, J., Barthel, M., \& Macnaughton, S. (2010). Food waste within food supply chains: Quantification and potential for change to 2050. Philosophical Transactions of the Royal Society of London B: Biological Sciences, 365(1554), 3065-3081.

[7] Lin, C. S. K., Pfaltzgraff, L. A., Herrero-Davila, L., Mubofu, E. B., Abderrahim, S., Clark, J. H., ... \& Thankappan, S. (2013). Food waste as a valuable resource for the production of chemicals, materials and fuels. Current situation and global perspective. Energy and Environmental Science, 6(2), 426-464.

[8] Huhtinen, K. (2009). Instruments for Waste Prevention and Promoting Material Efficiency: A Nordic Review. Nordic Council of Ministers.

[9] Deelstra, T., \& Girardet, H. (2000). Urban agriculture and sustainable

cities. http://citeseerx.ist.psu.edu/viewdoc/download?doi=10.1.1.16 $8.4991 \&$ rep=rep $1 \&$ type $=$ pdf.

[10] Martinez, S. (2010). Local food systems; concepts, impacts, and issues. Diane Publishing.

[11] Keller, K. L., \& Aaker, D. (1995). Managing the corporate brand: The effects of corporate images and corporate brand extensions. Research Paper 1216 , http://www.msi.org/reports/managing-the-corporate-brand-theeffects-of-corporate-marketing-on-consumer/.

[12] Keller, K. L. (1993). Conceptualizing, measuring, and managing customer-based brand equity. Journal of Marketing, 57(1), 1-22.

[13] Ahmad, M. F., Samsi, S. Z. M., Rasit, R. M., Yunus, N., \& Rahim, N. R. A. (2016). Corporate Social Responsibility for Takaful Industry's Branding Image. Jurnal Pengurusan (UKM Journal of Management), 46, 115-124. 
[14] Ailawadi, K. L., \& Keller, K. L. (2004). Understanding retail branding: Conceptual insights and research priorities. Journal of Retailing, 80(4), 331-342.

[15] De Castro, G. M., López, J. E. N., \& Sáez, P. L. (2006). Business and social reputation: Exploring the concept and main dimensions of corporate reputation. Journal of Business Ethics, 63(4), 361-370.

[16] Argenti, P. A., \& Druckenmiller, B. (2004). Reputation and the corporate brand. Corporate Reputation Review, 6(4), 368-374.

[17] Fombrun, C. J., \& Van Riel, C. B. (1997). The reputational landscape. Corporate Reputation Review, 1(2), 5-13.

[18] Papargyropoulou, E., Wright, N., Lozano, R., Steinberger, J., Padfield, R., \& Ujang, Z. (2016). Conceptual framework for the study of food waste generation and prevention in the hospitality sector. Waste Management, 49, 326-336.

[19] Aschemann-Witzel, J., de Hooge, I., Amani, P., Bech-Larsen, T., \& Oostindjer, M. (2015). Consumer-related food waste: Causes and potential for action. Sustainability, 7(6), 6457-6477.

[20] Papargyropoulou, E., Wright, N., Lozano, R., Steinberger, J., Padfield, R., \& Ujang, Z. (2016). Conceptual framework for the study of food waste generation and prevention in the hospitality sector. Waste Management, 49, 326-336.

[21] Girotto, F., Alibardi, L., \& Cossu, R. (2015). Food waste generation and industrial uses: A review. Waste Management, 45, $32-41$. 